\title{
Customization of Product Software: Insight from an Extensive IS Literature Review
}

\author{
Matthias Bertram, Mario Schaarschmidt, and Harald F.O. von Kortzfleisch \\ University of Koblenz-Landau \\ \{matthias.bertram, mario.schaarschmidt, \\ harald.von.kortzfleisch\} @uni-koblenz.de
}

\begin{abstract}
In recent years, companies started not only to ask customers by means of market research but to integrate them into the innovation process. Within information systems (IS) research, both customization as a way to serve the uniqueness of customers (inside-out) and as a form of customer integration and value co-creation (outside-in) has been considered. However, since many software vendors have consummated the shift from being manufacturers to being service firms, in practice, customization as a service highlights the continuance of customization projects. This paper addresses the research question of how concepts of customization are distinguished in recent IS literature. By conducting an extensive review of the IS literature between 2001 and 2011 we find that future research could benefit from considering knowledge interactions in customization processes more deeply.
\end{abstract}

Keywords: Customizing, Customization, Value Co-Creation, Information Systems, Literature Review.

\section{Introduction}

Companies increasingly need to understand their customers' wants and needs in order to strengthen their competitive positions. Thus, in recent years companies started not only to ask customers by means of market research but to integrate them into the innovation process [1, 2]. Concurrently, since the late 1970s the co-creation of value has become a field of intense research in marketing and service science. Researchers have analyzed co-creation under many different aspects as for example: productivity gains through customer self-service (e.g., [3], [4]), customer satisfaction, quality, employee's performance and emotional responses (e.g., [5]), and the opportunity to differentiate their products and services (e.g., [6]). Thereby, customization has emerged as a concept to provide customers with tailor-made products and services.

With respect to customization, researchers further concluded that customers may not be recognized as passive receivers, but should be seen as active and knowledgeable participants in common innovation or co-creation processes ([7]). For example, Firat et al. [8] introduced the concept of customerization and stated that it enables consumers to serve as the co-producer of the product and service offering. 
Relatedly, Ghosh et al. [9], who investigated the role of control in complex product customization, stated that success of customization is a function of the customer's knowledge. Thus, co-creation researchers assume an outside-in perspective of customization in that they focus on the integration of external resources into the innovation process.

Another stream of research pertaining to the concept of customization stems from economics and marketing. Here, researchers obtain an inside-out perspective in that they refer to customization as a way to tailor and deliver products and services according to customers' needs (e.g., [10]). They further highlight the role of mass customization as a customer specific production with near mass production efficiency and realization of economies of scales (e.g., [11], [12]).

However, the majority of articles in both areas have been written in a business-toconsumer (B2C) context, documented by the emphasis of the role of consumers and individual customers (e.g., [13], [14]). Within business-to-business (B2B) contexts, such as with the market for business software (e.g., enterprise resource planning (ERP) software), concepts such as mass customization are comparatively seldom because (1) buyers markets usually consist of only a few firms and (2) products are generally more complex than in B2C scenarios [9].

Given the importance of customization for an entire service industry (i.e. customization of business software such as SAP R/3) along with the scarce focus on integrative research studies in this field, a thorough analysis and synthesis of the concept is needed to promote future research. Against this background, the central research question of this paper is: How does current academic IS literature differ in definitions and applications of customization approaches in B2B scenarios? To answer this question, we conducted an extensive information systems (IS) literature review concerning the past decade. We draw on two different sources of academic IS literature: major journal papers including the IS senior scholars' basket of journals and conference proceedings.

The remainder of the paper is organized as follows. Section 2 provides a closer look at concepts and ideas of customization in the context of software products and exposes existing concepts and terms of customizing and (mass) customization. Section 3 describes the underlying research design including data collection, data analysis and results. In section 4, an interpretation of the results and a critical discussion is provided. The paper closes with a conclusions and implications for further research and practice.

\section{Related Work}

\subsection{Concepts of Product Software}

According to Sawyer [16] the concept of "make one, sell many" is common to all product software. He states that product software and tailor-made software can be distinguished by three major differences: First, while tailor-made software is oriented towards one customer, product software is market-oriented. Second, there are much more conditions for using a software product according to the hardware and software 
platform than for a tailor-made software which usually runs under one platform. And finally, with software products, the vendor usually retains the ownership of the software, while with tailor-made software all the corresponding artifacts (source code, documentation, etc.) are entirely sold to the customer.

From $\mathrm{Xu}$ and Brinkkemper's [17] perspective the process for developing product software consists of four development operations, Analysis of Requirements, Development, Delivery and Implementations Service. Each operation results in a stock or an IT artifact: Design Specification (D), Source Code (S), Delivered Software (P) and Running System (R). The biggest difference to the development process of tailormade software is that due to the number of customers and changing (business) re-quirements product software is almost never finished. With reference to other devel-opment processes such as eXtreme Programming, Scrum or the Rational Unified Process, $\mathrm{Xu}$ and Brinkkemper [17] state that the development of product software has a continual need for improvement and cannot be modeled in a sequential process.

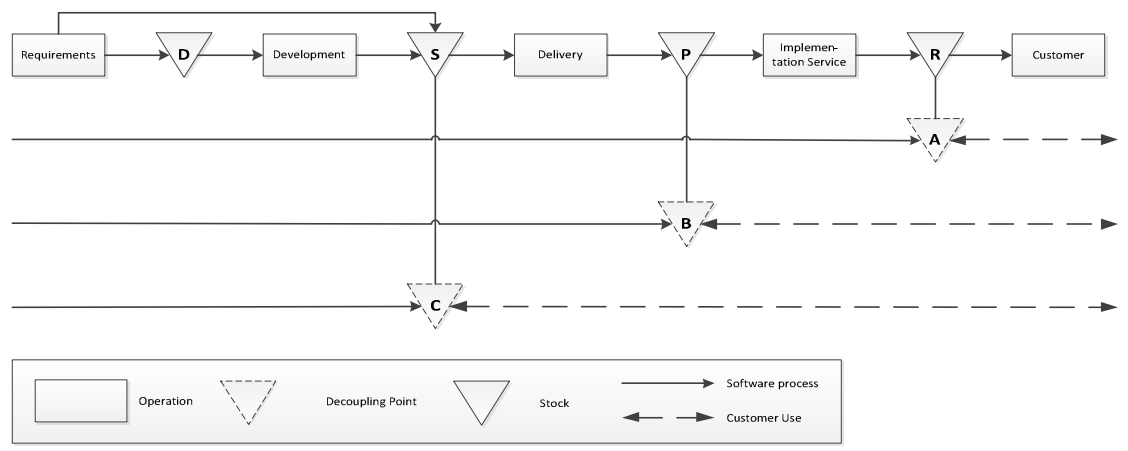

Fig. 1. Software production flow pipe-line (Source: adapted from Xu and Brinkkemper 2007)

From this perspective, product software can be classified into three categories according to the position of the decoupling point. The first category (C) is called semifinished-products which are software products like components or libraries that is intended to be sold to other business partners. The second category (B) self-install software contains software products, which can be sold by vendor and installed by the customer without special help. The third category (A) includes software products that require professional help for implementation (i.e. customizing) into the business (Figure 1).

\subsection{Customization of Product Software}

In the early days of software development, when software and hardware was still closely bundled, the prices for those systems were extremely high since the market for software products was simply not existent. Usually those systems were solely developed for individual companies according to their individual needs and requirements. In the late 1960 s computer manufactures started to unbundle hardware 
and software systems foundations as a result of an IBM initiative ([17]). As a consequence, an independent software market for business-to-business (B2B) was built where during 1980s, a new class of software vendors started to pre-built and offer software for ranges of business functions that could be delivered separately in large scales.

However, to address each customer's wants and needs, software was designed in a way that each customer could adapt certain parts without changing the source code of the software (e.g., changing a desktop background, hiding navigation, etc.). Today, global enterprise software companies such as SAP, Oracle and Microsoft generally develop product software for wider, more anonymous (B2B) markets or industries. In these cases, requirements usually are not fully specified and are worked out in implementation projects with customers. Thereby, customization in information systems can be understood as a special type of co-creation of value and late product differentiation. The economic importance of those customization projects is very high. For example IBM's total revenue in 2007 was \$99B with more than $50 \%(\$ 54 \mathrm{~B})$ resulting from consulting services including customization ([18]).

As discussed, the service of customizing complex product software has become business itself. Crucial to the existence of this service industry is that large business software requires changes at the source code level in order to be adapted to a user firm's need. In addition, as shown by Ghosh et al. [9] for mechanical industries, within software customizing projects, the project success is a function of the customer's knowledge. In particular, compared to mass customization in B2C scenarios where customers can chose colors or materials of the desired product ([19]), due to the complexity of business software, the customer usually is not able to communicate the needs in a proper way. In addition, the professional customer's needs change due to environmental turbulences and market dynamics. Consequently, the process of adapting a software product according to the professional customer's need drags on and demands several iterations. Thus, instead of communicating needs just once as in the case of mass customization in B2C contexts, customizing complex product software requires an iterative approach and is dependent on the customer's knowledge as well as his ability to communicate needs.

Based on our preliminary insights we provide the following working definition of customization for our analysis, knowing that customization in general and mass customization in particular need to be distinguished more specifically:

Customization is the process of configuring, parameterizing, or generally adopting an IS artifact to a customer's need.

\section{Research Approach}

According to authors such as Huff [20] or Creswell [21], one of the most well-established methods to integrate research findings and assess the cumulative knowledge within a domain is a qualitative literature review. This method allows 
researchers to analyze and evaluate both qualitative and quantitative literature within a research domain to draw conclusions about a state of a field. Since this method is well-established, researchers have already performed and adopted it to their needs and thereby developed several approaches to reviewing literature. For example, Huff [20] differentiates between at least four types of literature reviews: (1) survey to identify key issues and trends, (2) critical review to identify arguments, standards and potential for new contributions, (3) systematic review to expose quantitative and qualitative results across several areas of interest and (4) supportive review to generate new ideas and to resolve specific problems from existing literature. Those four differ in for example in purpose and primary and secondary sources of literature.

The research aim of this paper is to draw a coherent picture of ideas and concepts of customization in current IS literature and thereby helps to categorize existing ideas and concepts and furthermore identify potentials for future contributions to that field. Hence, according to Huff's [20] systematic of literature reviews this paper uses a critical review approach.

Since journal and conference publications are both a very accepted way to communicate research findings to the IS research community and referring to Webster and Watson [22], major IS-journals and -conferences were chosen as primary sources for the review. By adopting Jourdan et al.'s [23] research approach, we decided to split our research design into two sequential phases. The aim of the first phase was to identify relevant papers in mayor IS journals/conferences. During the second phase, an in-depth analysis of the selected papers was conducted (Figure 2).

In phase 1, we first determined the pool of journals and conference proceedings relevant to our study. For journals, we concentrated on the senior scholars' basket of journals that embrace six journals (i.e. MIS Quarterly, Information Systems Research, Journal of Management Information Systems, Journal of the Association for Information Systems, European Journal of Information Systems, Information Systems Journal) as well as on journals as recommended by Fisher et al. [24], Jourdan et al. [23], and Mustafee [25]. For conferences, we decided to include the proceedings of the International Conference on Information Systems (ICIS) and European Conference on Information Systems (ECIS). Additionally, the proceedings of the Wirtschaftsinformatik conference was included since this conference is (1) the major German speaking conference for IS research and (2) receives a higher share of design-oriented papers ([26]) what we consider important concerning our aim to provide a coherent picture of customization.

We used the ISI Web of Knowledge as well as the electronic library of the Association of Information Systems (AISel) to find potential papers for our review. We used the search functionality of each database to search titles and abstracts of the research articles using the phrases "customizing", "customizing", "customisation", and "customisation" and a publication date between 2001 and 2011. While the search engine and interface in the case of ISI Web of Knowledge was very user friendly, a little more handwork was needed in the case of the AISel because we were not able to restrict the search to the designated conferences. In the end we were able to build a superset of 84 journal articles and 23 conference proceedings for our research. 
Table 1. Results after research phase 1

\begin{tabular}{lllrr}
\hline$\#$ & \multicolumn{1}{c}{ Journal } & Acronym & \# Articles & \# Preselect \\
\hline 1 & MIS Quarterly & MISQ & 8 & 4 \\
2 & Information Systems Research & ISR & 7 & 3 \\
3 & Communication of the ACM & CACM & 3 & 2 \\
4 & Journal of Management Information Systems & JMIS & 5 & 5 \\
5 & Management Science & MS & 16 & 15 \\
6 & Journal of the ACM & JACM & 0 & 0 \\
7 & European Journal of Information Systems & EJIS & 9 & 9 \\
8 & IEEE Transactions on Software Engineering & IEEETSE & 8 & 4 \\
9 & Information Management & I\&M & 4 & 1 \\
10 & Harvard Business Review & HBR & 20 & 8 \\
11 & Wirtschaftsinformatik & WI & 4 & 3 \\
\hline & Total Journals & & $\mathbf{8 4}$ & $\mathbf{5 4}$ \\
\hline
\end{tabular}

\begin{tabular}{lllrr}
\hline$\#$ & \multicolumn{1}{c}{ Proceedings } & Acronym & \# Articles & \# Preselect \\
\hline 1 & European Conference on Information Systems & ECIS & 12 & 6 \\
2 & International Conference on Information Systems & ICIS & 5 & 3 \\
3 & Wirtschaftsinformatik & WIP & 6 & 2 \\
\hline & Total Proceedings & & $\mathbf{2 3}$ & $\mathbf{1 1}$ \\
\hline & Total & & $\mathbf{1 0 7}$ & $\mathbf{6 5}$ \\
\hline
\end{tabular}

As a last step in our research phase 1, based on the abstract we preselect relevant articles for our further analysis. As a code for the categorization we used a very simple $\mathrm{A}, \mathrm{B}$ and $\mathrm{C}$ scheme, where A meant the article fits greatly our topics (i.e. customization in IS and B2B), C it doesn't fit at all and B somewhere in between the former two. Two of the three authors assigned each publication to a category based upon the reading of abstracts. If both authors came to the same conclusion, the focal publication was assigned to the chosen category. For papers that have been assigned to different categories by the authors $(\mathrm{N}=18)$, both authors agreed to a common category after a rigorous discussion. In the end, all articles within category A and B were considered to be relevant for this research. Finally, we ended up with a set of 54 journal papers and 11 conference papers. Table 1 summarizes the results of research phase 1 .

After the pre-selection process we organized phase 2 - the in-depth analysis of the papers - as follows. Subsets of the research papers were allocated to each author; taking care that each subset consisted of papers from heterogeneous sources (i.e. a mixture of journals and conference proceedings).

For each paper in his subset each author had to identify the underlying research approach and definitions for customization concepts. We determined that each researcher had to analyze not more than three papers a week and that the findings had to be presented and discussed in weekly feedback meetings. Therefore, it was possible to organize an efficient research process which on the one hand allows a discourse on single papers and on the other hand avoided researcher fatigue. 
Using this approach we were able to resolve disagreements and provide consensual results for each paper. Table 2 provides an extract of the most interesting results of research phase 2 , grouped into customization as a form of delivery and a form of co-creation of value. ${ }^{1}$

Table 2. Extract of results after research phase 2

\begin{tabular}{lll}
\hline Author & Definition / Concept & Paper Type \\
\hline Customization as form of distribution & $\begin{array}{l}\text { Computer workarounds are a post-implementation Case study } \\
\text { phenomenon widespread in organizations. They are } \\
\text { commonly defined as non-compliant user behaviours } \\
\text { vis-à-vis the intended system design, which may go so } \\
\text { far as to bypass the formal systems entirely. }\end{array}$ \\
\hline [28] & $\begin{array}{l}\text { Although known primarily as a production principle Conceptional } \\
{[\ldots], \text { mass customization has also been applied to paper }} \\
\text { intangible products [...] focus distributive and market- } \\
\text { ing aspects when mass customizing offerings and } \\
\text { deals. }\end{array}$ \\
\hline
\end{tabular}

One important question in packaged software design Case study (Parand consumption is determining what the software can ticipation) and will do, in supporting, changing, and inhibiting desired organizational practices.

[30] This improvement in manufacturing flexibility allows mass customization of consumer products without significantly compromising cost efficiency. Not surprisingly, mass customization has begun to erode the domain of mass-produced standard items.

[31] Both [OS and COTS software] need to be customized Action research to fit the requirements of the adopting organization. Configuration and parameterization are the approaches of choice in this case. If they are not sufficient, customization of the SW code is necessary.

The internet has increased the expectation of customers for complete customization at a nominal charge. paper Even before the advent of e-business, firms faced the challenge related to mass customization and high productivity variety, but this has increased immensely over the last few years.

\footnotetext{
${ }^{1}$ The entire list of journal articles and conference papers is available upon request.
} 
Table 2. (continued)

Packaged enterprise software is ready-made mass Conceptional product offing users a solution based design process paper (Qualitiaaimed at generic customer groups in a variety of in- tive interviews) dustries and geographical areas. Packaged software can be contrasted with custom-built approaches, based on the organization of the development and delivery process. of individualization in the field of mass customization.

\section{Customization as co-creation}

Within mass customization, customers are integrated Conceptual into value creation by defining, configuring, design- paper ing, matching, or modifying their individual solution out of a list of options and pre-defined components.

[36] In such cases, clients can either change their organizational practices to fit the software or customize the development software application to fit their needs at some cost.

The goal of SPLs is to improve productivity, time-tomarket, and quality of application development by paper leveraging the commonalities of systems within an application domain while managing their variations. SPLs package these commonalities in domain-specific platforms, which may be customized through configuration settings or code extensions.

A related stream of research has focused on the tailor- Interviews ing of software methods to the actual needs of the development context. Factors such as organizational issues [...], distributed teams [...], or the existence of legacy systems $[\ldots]$ often require the use of a different method, or at least changes to the existing method.

Process customization or tailoring involves adapting, Case study particularizing, or selecting certain (often standard or (Qualitative "best practice") software processes to fit the needs of interviews) specific organizations or projects. 


\section{$4 \quad$ Findings and Discussion}

\subsection{Levels of Customization}

While there is a common understanding of customization as the adaption of software products, or more general IT artifacts, to specific customer's needs, the existing IS literature primarily uses concepts of customization from other disciplines. For example, the term mass customization was almost always defined in relation to industrial contexts without providing a sufficient definition in relation to characteristics of IS artifacts. Furthermore, the literature differs to a great extend in describing the level of customization since the term is used for configuration, parameterization, as well as adaption or development of existing or new source code.

Due to customer as well as vendor related reasons, the intensity of interaction in customization projects can be very high. For instance, because of a high level of innovation neither the customer nor the vendor is able to pre-estimate the effort to implement desired functionalities [29, 33]. In these cases, customization involves the customer's support to understand and change his own processes (e.g., by means of consulting services). On the vendor side, the software product's "manufacturing flexibility" or architectural agility may not be sufficient to implement the desired functionality in a standardized way and, for example, the source code has to be changed [31]. From our perception of customization in IS studies under investigation we define customization (in general) as a highly iterative form of IS implementation or adaption, where vendor and customer interactions are so intensive that it is not possible to handle them in single iterations of knowledge transfer.

Customization is the process of configuring, parameterizing or in general adopting an IS artifact to a customers need, in more than one iteration. In this case either the customer is NOT able to communicate his requirements in one step OR the vendors' manufacturing and distribution system is NOT capable to deliver the customized artifact in one additional step and a more intensive interaction between those two parties is necessary.

In contrast, mass customization focuses on the efficiency aspect of customization. The term was initially introduced by Davis [41] and later defined in the work of Tseng and Jiao [12] on industrial engineering as "producing goods and services to meet individual customer's needs with near mass production efficiency". Within IS, product configuration is an instrument to implement mass customization [34]. Due to the efficiency aspect of mass customization, the customer has to have a sufficient understanding of his requirements on the one hand and the vendors' delivery system has to be flexible (and standardized) enough to integrate this requirements in the existing product. Thus, at least one iteration of knowledge transfer occurs: The customer provides his knowledge on the requirements to the vendor and the vendor reacts by delivering a customized product. With respect to IS research and regarding the efficiency aspect of mass customization, we define it as follows: 
Mass customization is the process of configuring, parameterizing or generally adopting an IS artifact to a customer's need in one iteration. This happens only if the customer is able to communicate his requirements in one step and the vendor's manufacturing and distribution system is capable to deliver the customized artifact in one additional step.

\subsection{Intentions of Customization}

Customization as a Way to Deliver Software Products. As expected, customization seems to be a central topic in IS research. Predominantly, researchers focus on the way of how software is delivered to customers in relation to distribution economics[28, 33, 34]. Packaged software, as one incarnation of product software, has been one way to address the challenges of customization in many articles of our review. For example, Van Fenema et al. [33] described packaged software as "ready-made mass product offering users a solution based design process aimed at generic customer groups in a variety of industries and geographical areas." A more general focus is delivered by Chiasson and Green's [29] definition of packaged software, who argue that an important question in packaged software design and consumption is determining what the software can and will do, in supporting, changing, and inhibiting desired organizational practices.

In a similar vein, Sia and Soh [40] describe the package-organizational fit as the central point of interest for package customization. Regarding uncertainty in customization projects, Safadi and Faraj [27] describe workarounds as a valid way to address requirements that have not been foreseen during the development or implementation of a software package. They define this post-implementation phenomenon as a noncompliant user behavior vis-á-vis the intended system design. Although in extreme cases formal systems are entirely bypassed, workarounds are widely spread among organizations. From an architectural point of view Czarnecki et al. [37] describe software product lines as a tool "to improve productivity, time-to-market, and quality of application development by leveraging the commonalities of systems within an application domain while managing their variations" to address some of the above described challenges.

So far, a considerable stream of research addresses the way of distribution (i.e. packaging) of product software and regards customization in an "after-production"sense. As this perspective accrued from a logic in which a product is first produced and then distributed, it corresponds with the inside-out perspective of customization in IS introduced earlier.

Customization as the Co-creation of Value. Another stream of research in IS literature addresses the development side of software as well as customer integration during the development processes in particular. For example, Piller et al. [35] state that "with in mass customization, customers are integrated into value creation by defining, configuring, designing, matching, or modifying their individual solution out of a list of options and pre-defined components". In a similar vein Xin and Levina [36] 
argue that clients not only customize the software to their needs, but also change organizational practices to fit the software product.

Additionally, research has focused on the tailoring of software methods to development contexts. Fitzgerald et al. [38] argue that factors such as organizational issues, distributed teams, and the existence of legacy systems require different or changed development methods. In a similar vein, Slaughter et al. [39] describe the strategy and process fit as important for the development process. From their point of view, process customization or tailoring is important to fit the needs of specific organizations or projects. This involves adapting, particularizing, or selecting certain software processes.

In summary, a considerable stream of research addresses customization as a form of co-creation of value and thus supports our notion of a distinct outside-in perspective of customization in IS.

\subsection{Customization as a Service and Future Directions}

As expected, IS literature has paid attention to both customization as a form to realize economies of scales by using "make one, sell many "-approaches (inside-out) as well as a way of integrating customers into the innovation process (outside-in). Surprisingly, the combination of both perspectives has somewhat been neglected by IS research. Regarding customization as understood in practice, that is, the service of customization of large business software in B2B contexts, the customer provides his knowledge in his area of expertise as well as his requirements in multiple iterations. Thus, the customer complements the vendor's knowledge at a technological and at a market level not only at a distinct point in time as, for example, with mass customization, but continuously. Because receiving formulated requirements frequently is demanding, vendors in a customization scenario must develop a particular absorptive capacity [43] to be able to benefit from external knowledge sufficiently. However, as our review shows, reciprocal knowledge flows within IS literature pertaining to customization and customizing are largely neglected.

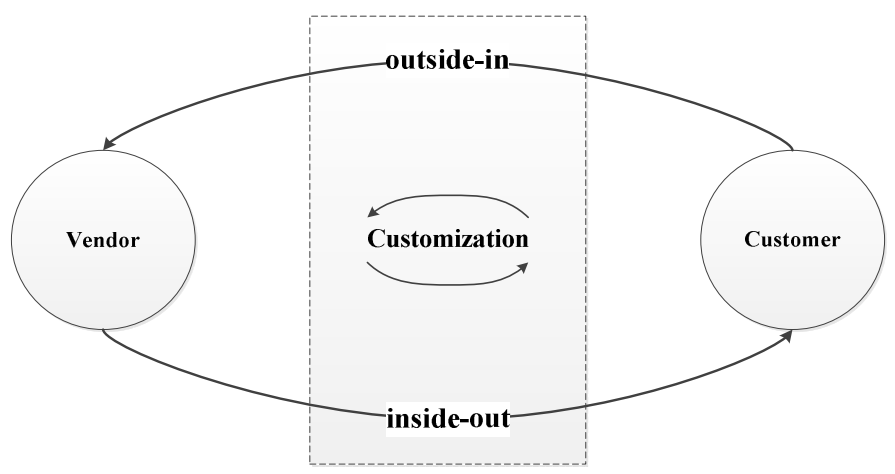

Fig. 2. Customizing as an iterative-circular process of knowledge flows 
In summary, from our observation we posit that the existing literature is anemic to knowledge transfer between vendor and customer in multiple iterations which drives us to delineate future research areas. To clarify our assumptions, Figure 3 shows the reciprocal "inside-out" and "outside-in" relationship between vendor and customer. For the reason of simplicity we left intermediates such as consultants and professional services out and sub summated them under the term vendor. While our research results highlight the differences in definition and application of customization concepts in IS literature, we recognize several aspects where further research in this area is needed.

First, as our review revealed, current studies differentiate customization by the means of level (customization and mass customization) and intention (co-creation of value and product distribution). Although existing literature considers those aspects to a certain extent, it lacks research studies that integrate the accumulated body of research. For instance, while literature differentiates the level of customization regarding customization (in general) and mass customization approaches, further studies are needed investigating the influence of the underlying customization technique on those levels. So far, existing literature describes product configuration as a tool for implementing mass customization functionality. Considering our definition of customization and mass customization based on interaction efficiency, mass customization might also be implemented using other techniques such as parameterization or source code development. Additionally, further research studies are needed investigating how customization intention influences software product management and vice versa. For instance, from a vendor perspective co-creation of value projects might be valuable for the orientation of the software product. From this point of view such projects can be considered a crucial investment in software product management. Here, future research should focus on what are the drivers and barriers of those customization activities and how vendors value and balance co-creation of value and product distribution projects.

Second, as already mentioned, customization strongly depends on the interaction and the knowledge transfer between vendors and customers. Considering customization as a service, a reciprocal knowledge exchange from vendor to customer (insideout) and customer to vendor (outside-in) can be assumed. In this area further research is needed investigating the influence of customization level and intention on characteristics and transfer of exchanged knowledge. Regarding the level of customization, we assume that due to interaction intensity with respect to tangible and intangible knowledge, customization (in general) is a richer medium of knowledge transfer than mass customization. On the other hand, within mass customization the vendor's manufacturing system has to be close to the customers' requirements to provide efficient customization functionality. In this case, we assume that the vendor has already a certain knowledge base about the topic of interest, which facilitates the exploration and assimilation of new knowledge. Here we state that future research in the context of customization should place more emphasis on knowledge characteristics and knowledge exploration, assimilation and exploitation processes.

Finally, if customization of large product software is regarded as a full service with multiple rounds of knowledge transfer between vendor and customer instead of a 
'one-time-only' on-top service for software goods, several issues such as customer integration and satisfaction have to be reconsidered in relation to innovation. Here, further research is needed that (1) identifies the factors that influence the success of customization projects on both vendor and customer side, that (2) considers the reciprocal nature of knowledge transfer with regard to the tension between vendors service delivery and innovation activities (i.e. standard product development), and (3) that investigates service properties (e.g., high vs. low degree of product customization) in relation to customer outcomes.

\section{Conclusion}

In this article, we provided an intensive review of the literature of the past ten years on customization and customizing aspects of B2B software in the IS field. Although this timeframe partly limits the generalizability our research results, it reflects recent developments in the software markets such as the rising complexity of software system which increases the need for customization.

We found support for the notion of customization as a form of co-creation of value between vendors (also intermediates like consultants/professional services) and customers as well as for how widely spread the phenomenon is in the IS field. Similarly, we found support for an inside-out perspective of customization in that customization is understood as a form of software delivery. Furthermore, we described why the degree of customization is strongly dependent on the software product itself and the decoupling point where the customer comes into place during the development process and they criticize that many packages are not able to address important needs and expectations of organizations.

Our literature review revealed that even being an issue of interest in IS research for quite a period, concepts of customization have still not been defined sufficiently. Terms such as mass customization and customization are often used inconsistently (and sometime even interchangeably) or are provided with poor definitions referring to other disciplines. By providing definitions of customization and mass customization based on knowledge and vendor-customer interactions, we contribute to IS in general and software engineering in particular. Our research may act as a starting point for deeper and further-reaching contributions to this field of interest, regarding the tension between standardization (product software) and individualization (tailor-made software) under consideration of vendor and customer requirements. We further call for more in-depth studies that consider the role of knowledge exchange in customization of IS artifacts.

\section{References}

1. Prahalad, C.K., Ramaswamy, V.: Co-opting customer experience. Harvard Bus. Rev. 78(1), 79-88 (2000)

2. Von Hippel, E.: Democratizing Innovation. MIT Press, Cambridge (2005) 
3. Czepiel, J.A.: Service encounters and service relationships: Implications for research. J. Bus. Res. 20(1), 13-21 (1990)

4. Kelley, S.W., Donnelly, J.H., Skinner, S.J.: Customer participation in service production and delivery. J. Retailing 66(3), 315-335 (1990)

5. Bendapudi, N., Leone, R.P.: Psychological implications of customer participation in co-production. J. Marketing 67(1), 14-28 (2003)

6. Song, J.H., Adams, C.R.: Differentiation through customer involvement in production or delivery. J. Consum Marketing 10(2), 4-12 (1993)

7. Nambisan, S.: Designing virtual customer environments for new product development: Toward a theory. Acad. Manage. Rev. 27(3), 392-413 (2002)

8. Firat, A.F., Dholakia, N., Venkatesh, A.: Marketing in a postmodern world. Eur. J. Marketing 29(1), 40-56 (1995)

9. Ghosh, M., Dutta, S., Stremersch, S.: Customizing Complex Products: When Should the Vendor Take Control? J. Marketing Res. 43(4), 664-679 (2006)

10. Franke, N., Keinz, P., Steger, C.: Testing the value of customization: When do customers really prefer products tailored to their preferences? J. Marketing 73(5), 103-121 (2009)

11. Kotler, P.: From mass marketing to mass customization. Strategy and Leadership 17(5), 10-47 (1989)

12. Tseng, M.M., Jiao, J.: Mass customization. In Handbook of Industrial Engineering, Technology and Operation Management, 3rd edn. Wiley, New York (2001)

13. Etgar, M.: A descriptive model of the consumer co-production process. J. Acad. Marketing Sci. 36(1), 97-108 (2008)

14. Franke, N., Schreier, M.: Product uniqueness as a driver of customer utility in mass customization. Marketing Letters 19(2), 93-107 (2007)

15. Müller, J., Krüger, J., Enderlein, S., Helmich, M., Zeier, A.: Customizing enterprise software as a service application: Back-end extension in a multi-tenancy environment. Enterprise Inform. Syst. 24(1), 66-77 (2009)

16. Sawyer, S.: A market-based perspective on information systems development. Commun. ACM 44, 97-102 (2001)

17. Xu, L., Brinkkemper, S.: Concepts of product software. Eur. J. Inform. Syst. 16(5), 531-541 (2007)

18. Spohrer, J., Maglio, P.P.: The emergence of service science: Toward systematic service innovations to accelerate co-creation of value. Prod. Oper. Manage. 17, 238-246 (2008)

19. Reichwald, R., Piller, F.T.: From mass production towards customer integration and co-production. Wirtschaftsinformatik 45(5), 515-519 (2003)

20. Huff, A.S.: Designing Research for Publications. Sage Publications, London (2008)

21. Creswell, J.W.: Research design: Qualitative, quantitative, and mixed methods approaches, 3rd edn. Sage Publication, London (2009)

22. Webster, J., Watson, R.T.: Analyzing the past to prepare for the future: Writing a literature review. MIS Quart 26(2), 8-13 (2002)

23. Jourdan, R.Z., Kelly, R., Marshall, T.E.: Business intelligence: An analysis of the literature. Inform. Syst. Manage. 25(2), 121-131 (2008)

24. Fisher, J., Shanks, G., Lamp, J.: A ranking list for information systems journals. Austral. J. Inform. Syst. 14(2), 5-18 (2007)

25. Mustafee, N.: Evolution of IS research based on literature published in two leading IS journals - EJIS and MISQ. In: Proceedings of the European Conference on Information Systems (2011), http: / /aisel.aisnet.org/ecis2011/228 
26. Oesterle, H., Becker, J., Frank, U., Hess, T., Karagiannis, D., Krcmar, H., Loos, P., Mertens, P., Oberweis, P., Sinz, E.: Memorandum on design-oriented information systems research. Eur. J. Inform. Syst. 20, 7-20 (2010)

27. Safadi, H., Faraj, S.: The role of workarounds during an opensource electronic medical record system implementation. In: Proceedings of the International Conference on Information Systems (2010), http: / / aisel . aisnet.org/icis2010_submissions

28. Brocke, H., Ubernickel, F., Brenner, W.: Mass customizing IT service agreements: T owards individualized on-demand services. In: Proceedings of the European Conference on Information Systems (2010), http: / / aisel . aisnet .org/ecis2010/101

29. Chiasson, M.W., Green, L.W.: Questioning the IT artefact: user practices that can, could, and cannot be supported in packaged-software designs. Eur. J. Inform. Syst. 16(5), 542-554 (2007)

30. Dewan, R., Jing, B., Seidmann, A.: Product customization and price competition on the Internet. Manage. Sci. 49(8), 1055-1070 (2003)

31. Keßler, S., Alpar, P.: Do best practice frameworks fit open source software customization? In: Proceedings of the European Conference on Information Systems 2008 (2009), http: //aisel.aisnet.org/ecis2008/20

32. Swaminathan, J.M., Tayur, S.R.: Models for supply chains in e-business. Manage. Sci. 49(10), 1387-1406 (2003)

33. Van Fenema, P.C., Koppius, O.R., van Baalen, P.J.: Implementing packaged enterprise software in multi-site firms: intensification of organizing and learning. Eur. J. Inform. Syst. 16(5), 584-598 (2007)

34. Weinmann, M., Robra-Bissantz, S., Witt, M., Schmidt, E.: Einflussfaktoren auf die Präferenz bei Produktkonfiguratoren - Eine empirische Studie am Beispiel der Automobilindustri. In: Proceedings of Wirtschaftinformatik 2011 (2011), http://aisel.aisnet.org/ wi2011

35. Piller, F., Schubert, P., Koch, M., Möslein, K.: From mass customization to collaborative customer codesign. In: Proceedings of the European Conference on Information Systems 2004 (2004), http: / / aisel.aisnet.org/ecis2004/118

36. Xin, M., Levina, N.: Software-as-a service model: Elaborating client-side adoption factors. In: Proceedings of the International Conference on Information Systems (2008), http://aisel.aisnet.org/icis2008/86

37. Czarnecki, K., Antkiewicz, M., Kim, C.H.P.: Multi-level customization in application engineering - Developing mechanisms for mapping features to analysis models. Commun. ACM 49(12), 61-65 (2006)

38. Fitzgerald, B., Hartnett, G., Conboy, K.: Customizing agile methods to software practices at Intel Shannon. Eur. J. Inform. Syst. 15(2), 200-213 (2006)

39. Slaughter, S.A., Levine, L., Ramesh, B., Pries-Heje, J., Baskerville, R.: Aligning software processes with strategy. MIS Quart. 30(4), 891-918 (2006)

40. Sia, S.K., Soh, C.: An assessment of package-organisation misalignment: institutional and ontological structures. Eur. J. Inform. Syst. 16(5), 568-583 (2007)

41. Davis, S.: Future Perfect, 10th anniversary edition. Addison-Wesley Pub. Co, Harlow (1996)

42. Lakhani, K., Von Hippel, E.: How open source software works: Free user-to-user assistance. Res. Policy 32, 923-943 (2003)

43. Lichtenthaler, U.: Absorptive capacity, environmental turbulence, and the complementarity of organizational learning processes. Acad. Manage. J. 52(4), 822-846 (2009) 